\title{
After the asthmas: Star Wars and Star Trek
}

\author{
Andrew Bush ${ }^{1}$ and lan D. Pavord ${ }^{2}$
}

Affiliations: ${ }^{1}$ Paediatrics, Imperial College, National Heart and Lung Institute, Royal Brompton Harefield NHS Foundation Trust, London, UK. ${ }^{2}$ Respiratory Medicine Unit and Oxford NIHR Biomedical Research Centre, Nuffield Department of Medicine, Oxford, UK.

Correspondence: Dept of Paediatric Respiratory Medicine, Royal Brompton Hospital, Sydney Street, London SW3 6NP, UK. E-mail: a.bushवimperial.ac.uk

@ERSpublications

The Lancet commission on asthma proposes new paradgims; especially to ask "what asthma do I have?" http://ow.ly/YVpG30eaeN5

Cite this article as: Bush A, Pavord ID. After the asthmas: Star Wars and Star Trek. Eur Respir J 2017; 50: 1701362 [https://doi.org/10.1183/13993003.01362-2017].

\begin{abstract}
A long time ago in a galaxy far, far away (1958, Derby, UK in fact), Harry Morrow-Brown used his microscope from his medical school days to show that only those adults with airway disease and sputum eosinophilia responded to oral prednisolone [1], thus preventing this most powerful of medications being consigned to the asthma dustbin of history. Subsequent work led to steroid therapy moving from oral to inhaled [2], and thus nearly three decades ago came, not the dawning of the Age of Aquarius, but that of the age of inhaled corticosteroids (ICS). This age brought undoubted and huge benefits, and there can be no question but that low dose ICS when regularly and properly administered are one of the safest and most effective treatments in the respiratory armamentarium. However, in the aftermath of the discovery of a really effective treatment, instead of kicking on to the next stage, we have stagnated in an unsatisfactory comfort zone. Asthma diagnosis is inaccurate [3-5], but this does not matter, because ICS are so safe you may as well try them for any respiratory symptoms, and anyway, there is a big placebo effect. Medications are escalated uncritically, without thought as to why low doses are not working. Asthma mortality does remain unacceptably high [6], a red flag in our present morass of complacency. Finally, we get into sterile debates about whether, for example, survivors of pre-term birth have "asthma". Crucially, we have lost sight of the great lesson taught to us by Dr Morrow-Brown, namely that all asthmas are not equal. The age of ICS, which started as the first use of personalised treatment, did not become the platform for building precision medicine, but instead, has reached an era of "put steroids in the tap water", and writing and re-writing "evidence based guidelines", which assume homogeneity and have signally failed to improve outcomes, while replacing serious thought about the problems.
\end{abstract}

This is the context which has led to a Lancet commission, "After Asthma: defining airways disease" [7]. The basic premise is that "asthma" as a term is no more a diagnosis than "arthritis", "anaemia" or "uraemia". Like these other non-specific terms, asthma should be taken to be no more than an umbrella collection of symptoms and signs; in the case of asthma, cough, breathlessness, chest tightness and wheeze. To define asthma solely using this constellation of symptoms immediately leads to the appropriately focused question, "what sort of asthma do I have?" Hence we have pulled together experts from across the

Received: July 072017 | Accepted: July 092017

Support statement: A. Bush is an NIHR Senior Investigator and additionally was supported by the NIHR Respiratory Disease Biomedical Research Unit at the Royal Brompton and Harefield NHS Foundation Trust and Imperial College London. I.D. Pavord is an NIHR Senior Investigator and additionally is supported by the Oxford Respiratory Biomedical Research Centre.

Conflict of interest: Disclosures can be found alongside this article at erj.ersjournals.com

Copyright CERS 2017 
globe with different research interests to try to move us out of conventional silos (age, discipline, disease and nationality) to try to move us out of our present comfort rut, specifically to address the questions, "where are we now?" and "where do we think we want to go?" in order to challenge dogma. As Hilaire Belloc famously wrote, "Oh! Let no-one ever, ever doubt, What nobody is sure about!"

The commission proposes two interlinked approaches to move the field forward. The first is reductionist, in the clinic, to be used now: airway disease should be deconstructed into its component parts, with particular emphasis on "treatable traits" [8]. These components are airflow limitation (fixed and variable), airway inflammation (eosinophilic, neutrophilic, both or neither, and increasingly important in the age of ever more diverse monoclonals, pathway based), airway infection and disordered airway defence mechanisms (i.e. cough reflex hypersensitivity). Central to this is the evidence based belief that not all the asthmas are inflammatory diseases, and bronchodilator responsiveness and inflammation are no more related than body mass index and brain power. Furthermore, airway disease must be seen in the wider context of comorbidities and the environment, including social behaviours, such as adherence [8]. Neglect of these dimensions, combined with a reliance on levels of prescribed treatment as the main determinant of severity, has led to the absurd position that most asthma deaths are in non-severe asthmatics [9] although the White Queen in Alice in Wonderland could believe six impossible things before breakfast, even she would surely have baulked at this! So the commissioners propose an alternative definition of severe asthma which takes into account these other factors.

However, reductionism is not of itself sufficient. We also need integrative systems biology approaches to understand the complexities of asthma phenotypes and their evolution over time; encouragingly, this approach is already being used (below). Important in this approach is the time domain; longitudinal studies are harder than cross-sectional, but complex mathematical analyses of simple data points may be hugely informative [10]. Furthermore, the complex interactions between a multiplicity of effects, and the developmental changes in these interactions, are only just beginning to be explored.

Another problem of the Tsunami of guidelines is that all majorly concern themselves with asthma as a chronic disease to be palliated rather than a disease we should be trying to prevent or cure. The result has been a focus on more "me-too" steroids and long-acting beta- 2 agonists, rather than a fundamental attack on root causes. We do not need more of these agents; those that we have are more than adequate for the task if properly used, as has been shown repeatedly when inhaled beclomethosone is introduced in low and middle income settings [11]. We need research to be focused on prevention and cure.

We also focus on two areas where progress is tantalisingly close, namely asthma attacks and really severe asthma. Asthma attacks have been another area where complacency reigns, reflected by the frequent use of the feeble word "exacerbation" $[12,13]$. We know that only a subpopulation of asthmatic people have asthma attacks [14], but these define a group at risk of further attacks, impaired lung growth [15] and thus later chronic obstructive pulmonary disease [16], and death from asthma. We need to identify these people and follow the lead of cardiology by responding to these "asthma lung attacks" with focus and determination to prevent recurrence; was there an asthma plan, was it followed, should it be altered? What went wrong and can we stop it happening again? We need to stratify risk, so we can really centre our efforts on this group. Encouragingly, there are a number of groups using systems biology to break away from the Orwellian mantra "more steroids good, even more steroids better" approach, by determining novel, non-TH2, driven pathways for which hopefully new treatments will come $[17,18]$.

The commissioners also call for better research. We must have done with the nonsense of clinical phenotyping using "doctor-diagnosed asthma", which we know is a lottery. Years ago, the CAMP study required demonstration of bronchial hyper-responsiveness for enrolment into a longitudinal study of more than 1000 children [19]; why have we not become even more stringent with time, rather than let intellectual sloppiness creep in? Sir Edmund Hilary famously said he climbed Mount Everest for the first time "because it was there"; this may be good enough motivation for a mountaineer, but not for a scientist choosing animal models of airway disease. When was the last time anyone saw a patient who had had allergen injected into the peritoneal cavity?

The commission is not, and not intended to be, a review article, but an opinion piece intended to stir up controversy, and move the reader to action, rage or both; we finish with seven recommendations (box 1). Whether you agree with all or none, if they provoke thought and a change of direction, we will feel we have achieved our aims.

And finally, a challenge. Of course monogenic diseases are easier than polygenic, with complex gene-environment interaction, but let us compare the pitiful lack of progress in asthma with the stellar exemplar of cystic fibrosis. In the 80 years since it was differentiated from other causes of chronic airway infection and wasting, the cystic fibrosis community has discovered specific diagnostic tests which can be 
BOX 1 Seven key points from the Lancet Commission

1) A revolution in thinking about asthma, generalisable to all airway diseases and delivering precision medicine: what asthma do I have?

2) Move beyond a disease control-based ambition for asthma treatment

3) Break out of our age- and discipline-related silos

4) Test before treat

5) Zero tolerance for attacks

6) Make the most of new treatment opportunities in severe disease

7) Better research

applied to newborns [20]; they have moved from firefighting the downstream consequences of disease to designer molecules [21], underpinning these advances with definitive randomised controlled trials [21, 22]; and are moving to personalised medicine testing molecules on organoids created from rectal biopsies [23], and biomarker driven detection of cystic fibrosis lung attacks [24, 25]. And asthma: it's the blue one, the brown one (maybe a bit bluer and a bit browner, but essentially with technology which has not changed in decades), measure the urinary cotinine, and stare menacingly at the pet cat [26]. Enough! Let us boldly go where no asthma doctors have gone before.

\section{References}

1 Morrow-Brown $\mathrm{H}$. Treatment of chronic asthma with prednisolone; significance of eosinophils in the sputum. Lancet 1958; 2: 1245-1247.

2 Morrow-Brown H, Storey G, George WH. Beclomethasone dipropionate: a new steroid aerosol for the treatment of allergic asthma. Br Med J 1972; 1: 585-590.

3 Looijmans-van den Akker I, van Luijn K, Verheij T. Overdiagnosis of asthma in children in primary care: a retrospective analysis. Br J Gen Pract 2016; 66: e152-e157.

4 Aaron SD, Vandemheen KL, FitzGerald JM, et al. Reevaluation of diagnosis in adults with physician-diagnosed asthma. JAMA 2017; 317: 269-279.

5 Bush A, Fleming L. Is asthma overdiagnosed? Arch Dis Child 2016; 101: 688-689.

6 Levy ML, Winter R. Asthma deaths: what now? Thorax 2015; 70: 209-210.

7 Pavord ID, Beasley R, Agusti A, et al. After asthma: redefining airways diseases. Lancet 2017; in press [https://doi. org/10.1016/S0140-6736(17)30879-6].

8 Agusti A, Bel E, Thomas M, et al. Treatable traits: toward precision medicine of chronic airway diseases. Eur Respir J 2016; 47: 410-419.

9 Royal College of Physicians. Why Asthma Still Kills. London, Royal College of Physicians, 2015. Available from: www.rcplondon.ac.uk/projects/outputs/why-asthma-still-kills

10 Frey U, Brodbeck T, Majumdar A, et al. Risk of severe asthma episodes predicted from fluctuation analysis of airway function. Nature 2005; 438: 667-670.

11 Soto-Martínez M, Avila L, Soto N, et al. Trends in hospitalizations and mortality from asthma in Costa Rica over a 12- to 15-year period. J Allergy Clin Immunol Pract 2014; 2: 85-90.

12 FitzGerald JM. Targeting lung attacks. Thorax 2011; 66: 365-366.

13 Bush A, Pavord I. Following Nero: fiddle while Rome burns, or is there a better way? Thorax 2011; 66: 367.

14 Puranik S, Forno E, Bush A, et al. Predicting severe asthma exacerbations in children. Am J Respir Crit Care Med 2017; 195: 854-859.

15 O'Byrne PM, Pedersen S, Lamm CJ, et al. Severe exacerbations and decline in lung function in asthma. Am J Respir Crit Care Med 2009; 179: 19-24.

16 Lange P, Celli B, Agusti A, et al. Lung-function trajectories leading to chronic obstructive pulmonary disease. $N$ Engl J Med 2015; 373: 111-122.

17 Kuo C-HS, Pavlidis S, Loza M, et al. T-helper cell type 2 (Th2) and non-Th2 molecular phenotypes of asthma using sputum transcriptomics in U-BIOPRED. Eur Respir J 2017; 49: 1602135.

18 Kuo C-HS, Pavlidis S, Loza M, et al. A transcriptome-driven analysis of epithelial brushings and bronchial biopsies to define asthma phenotypes in U-BIOPRED. Am J Respir Crit Care Med 2017; 195: 444-455.

19 The Childhood Asthma Management Program Research Group. Long-Term Effects of Budesonide or Nedocromil in Children with Asthma. N Engl J Med 2000; 343: 1054-1063.

20 Barben J, Castellani C, Dankert-Roelse J, et al. The expansion and performance of national newborn screening programmes for cystic fibrosis in Europe. J Cyst Fibros 2017; 16: 207-213.

21 Ramsey BW, Davies J, McElvaney NG, et al. A CFTR potentiator in patients with cystic fibrosis and the G551D mutation. N Engl J Med 2011; 365: 1663-1672.

22 Wainwright CE, Elborn JS, Ramsey BW, et al. Lumacaftor-ivacaftor in patients with cystic fibrosis homozygous for Phe508del CFTR. N Engl J Med 2015; 373: 220-231.

23 Dekkers JF, Berkers G, Kruisselbrink E, et al. Characterizing responses to CFTR-modulating drugs using rectal organoids derived from subjects with cystic fibrosis. Sci Transl Med 2016; 8: 344ra84.

24 Nick JA, Sanders LA, Ickes B, et al. Blood mRNA biomarkers for detection of treatment response in acute pulmonary exacerbations of cystic fibrosis. Thorax 2013; 68: 929-937.

25 Quon BS, Dai DL, Hollander Z, et al. Discovery of novel plasma protein biomarkers to predict imminent cystic fibrosis pulmonary exacerbations using multiple reaction monitoring mass spectrometry. Thorax 2016; 71: 216-222.

26 Rosenthal M. CON: encouraging resistance to rule-based medicine is essential to improving outcomes. Thorax 2015; 70: 112-114. 